\title{
Association between opioid use disorder (tramadol) and serum level of interleukin-2
}

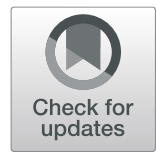

\author{
Alaa-Eldin Darweesh ${ }^{1}$, M. Agban², Mona H. Mohammed ${ }^{1}$ and Romany H. Gabra ${ }^{1 *}$ (D)
}

\begin{abstract}
Background: Tramadol hydrochloride is a centrally acting analgesic drug that has turned out to be a drug of growing interest due to its success in the management of pain in humans. By considering the twin mechanism of action of tramadol, as the activation of the opioid and of the monoaminergic systems, the potential immunological effects of this drug should be considered and be evaluated. Studies show that Tramadol induces an improvement of postoperative immune suppression and increases NK cell activity, lymphocyte proliferation, and IL-2 production which may be linked to its addictive potentiality. The present study aims to investigate the possible association between opioid use disorder (tramadol) and the serum level of interleukin-2 (IL-2).

An observational cross sectional study conducted at the Outpatient Clinic and Inpatient Unit of the Addiction Management Unit of the Neurology and Psychiatry Department of Assiut University Hospital. Assessment of serum level of IL-2 for 59 male patients diagnosed with opioid use disorder (tramadol) according to DSM-5 compared to 32 cross-matched male individuals as a control group.

Results: Comparing the serum level of IL-2 in patients with opioid use disorder (tramadol) with that of the controls, it was found that the patients with opioid use disorder (tramadol) have significantly higher serum level of IL-2 $(318.69 \pm 35.89)$ than that of controls $(260.45 \pm 30.08)(P=0.01)$. Patients with tramadol urine assay $(>200 \mathrm{ng} / \mathrm{ml})$ have significantly higher serum level of IL-2.

Conclusion: The current study found that patients with opioid use disorder (tramadol) have significantly elevated serum levels of IL-2 than healthy controls. Also, this elevation was dose related.
\end{abstract}

Keywords: Opioid, Tramadol, Interleukin-2

\section{Background}

Tramadol hydrochloride is one of the centrally acting analgesic drugs $[1,2]$ that has a low affinity for $\mu$ opioid receptors [3], while the M1 (metabolite 1 of tramadol), which is produced via O-demethylation, shows more affinity for opioid receptors than the parent drug $[3,4]$.

Also, tramadol has a large modulatory effect on central monoaminergic pathways, by inhibiting the reuptake of noradrenaline and serotonin in the brain and brain stem [5-8].

\footnotetext{
* Correspondence: romany_hosny27@hotmail.com

${ }^{1}$ Department of Neuropsychiatry, Assiut University Hospital, Faculty of Medicine, Assiut University, Asyut, Egypt

Full list of author information is available at the end of the article
}

Tramadol is used for the remedy of several sorts of pain of intermediate or severe intensity of various causes [5, 9]. Therapeutic use of tramadol which is usually not associated with the classical common side-effects of opiate drugs, such as respiratory depression, constipation, or sedation with lower dependence probability was recorded $[9,10]$.

Despite tramadol having a double mechanism of action (binds with low affinity to $\mu$-opioid receptors as synthetic opioids, and activates central monoaminergic pathways by inhibiting the neuronal uptake of serotonin and noradrenaline) $[7,8]$, it does not affect the immune system as morphine. In contrast to morphine, tramadol does not suppress cellular immune functions, but it increases NK activity, lymphocyte proliferation, and 
interleukin-2 production [2]. So the ability of tramadol to modulate immune reaction might be because of its coexisting intrinsic serotonergic effect $[2,11]$.

Cytokines play an essential role within the coordination and law of immune system [2, 11-14]. For example, interleukin-1 (IL-1), tumor necrosis factor- $\alpha$ (TNF- $\alpha$ ), and interleukin-6 (IL-6) have local and systemic effects that may restrict injury and the spread of infection and provide a suitable environment for tissue healing and repair [15].

Regarding interleukin-2, one of its most important functions is stimulating clonal expansion of activated Tlymphocyte [16], promoting B cell proliferation and immunoglobulin production [17], enhancing macrophage cytotoxicity [18], and supporting the growth of cytotoxic T-lymphocytes (CTL) [19] and natural killer (NK) cells [20]. Cytotoxic T-lymphocytes and NK cells kill virusinfected cells and some tumor cells [21].

While serotonin is not required for IL-2 production, increasing serotonin levels in the human brain can supplement a suboptimal stimulus to enhance IL-2 production [22].

Studies demonstrate that both endogenous and exogenous serotonin have regulatory effects on the $\mathrm{T}$ cell functions. Also, serotonin has been shown to enhance NK activity (including IL-2 activation of NK activity), by decreasing the suppressive effect of macrophages toward the NK cells. This effect was shown to be mediated by different serotonin receptors namely 5 -HT1A receptor $[23,24]$ and 5-HT2 receptor [22]. Another evidence is that several studies show that antidepressants increase the serum levels of IL-2 and IFN- levels via increased serotonin activity in the brain [25].

Once drug addiction has developed, it can be a lifelong condition in which individuals show intense craving and increased risk for relapse after years of abstinence, indicating that chronic drug exposure causes stable changes in the structure and function of the brain that may underlie the long-lived behavioral abnormalities in drug addiction [26].

It was reported that some of the neurotrophic factors and inflammatory cytokines (which have some effect on synaptic transmission and neuronal morphology) may be involved in changes of the morphology of dendrites and dendritic spines in certain brain reward centers as the nucleus accumbens and prefrontal cortex after repeated injections of psycho-stimulants [27-29].

IL-2 potentiates the DA uptake inhibitor GBR 12909induced exploratory activity (Vanoxerine (GBR-12909) is a piperazine by-product which is a potent and selective dopamine reuptake inhibitor), suggesting that this cytokine has modulatory effects on the mesocorticolimbic DA system [30]. IL-2 potentiates discriminative stimulus effects of amphetamine and ethylketocyclazocine [31].
IL-2 upregulates TLR4 surface expression on human peripheral blood monocyte [32]. TNF-alpha, IFNgamma, and IL-2 increase TLR-2 expression in immature dendritic cells [33].

The toll-like receptor (TLR) superfamily modulates pro-inflammatory responses to pathogens by sensing giant molecules containing lipids, sugars, protein, and nucleic acid components. Initial studies urged that solely microglia are involved in TLR signaling; however, newer studies suggest that all brain cell types are involved in this signaling [34]. Toll-like receptors activate signaling cascades that converge on nuclear factor kappa-lightchain-enhancer of activated B cells (NF-kB), a key innate immune nuclear transcription factor that promotes expression of pro-inflammatory cytokines, including tumor necrosis factor $\alpha(\mathrm{TNF} \alpha)$, interleukin-1 $\beta$ (IL-1 $\beta)$, IL-6, and monocyte chemo-attractant protein-1 (MCP-1) [35].

Repeated stress and cycles of alcohol and drug dependence sensitize the microglia, in line with the hypothesis that induction of innate immune signaling pathways contributes to the progressive increase in craving, mood dysfunction, and cognitive impairments recorded in addiction. Progressive signaling of this system leads to a progressive deterioration of behavioral control, increased impulsivity and anxiety, and negative affect and craving coupled with increasing ventral striatal responses to promote reward-seeking behaviors and increase the risk of developing alcohol and substance use disorders [35].

The development of tramadol as a significant drug problem is somewhat puzzling since, in the USA and different Western countries, illicit tramadol use and dependence is generally not considered a significant drug problem. It is usually considered a safer, less abusable medication as compared to more potent painkillers such as oxycodone and hydrocodone [36].

According to a 2012 national survey report in Egypt, cannabis is the most common drug of abuse within the country and around $9.6 \%$ of the population used other illicit drugs (a large proportion of which were tramadol users) [37]. This finding represents a dramatic increase within the range of patients illicitly using tramadol in Egypt in the last 10 years [38].

\section{Aim of the work}

The current study aims to investigate association between opioid use disorder (tramadol) and serum level of interleukin-2 (IL-2). As chronic tramadol use could increase the serum level of IL- 2 which may have a role in maintaining addictive behavior.

\section{Methods}

\section{Type and study setting}

The current study was an observational cross sectional study conducted at the outpatient clinic and inpatient 
unit of addiction management unit of the neurology and psychiatry department of Assiut University Hospital. Addiction management unit contains 16 beds, based on paid service and about 800 patients have been admitted per year; most of them have polysubstance use disorder including tramadol and others.

\section{Sample size}

Sample size was calculated according to the following equation:

$$
\begin{aligned}
\text { Sample size }(n)= & {[\operatorname{DEFF} \times \operatorname{Np}(1-p)] /\left[\left(d^{2} / Z^{2}{ }_{1-\alpha / 2}\right.\right.} \\
& \times(N-1)+\mathrm{p} \times(1-\mathrm{p})]
\end{aligned}
$$

where:

Population size (for finite population correction factor or fpc) $(N)$

Hypothesized \% frequency of outcome factor in the population $(p)$

Confidence limits as \% of 100 (absolute \pm \%) (d)

Design effect (for cluster surveys-DEFF) [39]

\section{Patients (sample)}

According to the previous equation the study included 59 male patients diagnosed as opioid use disorder (tramadol) according to DSM-5 and 32 cross-matched male individuals as controls. Those individuals were recruited randomly (during 6 days of work, only patients who come on Saturday, Monday, and Wednesday were included) during the period from first of December 2016 to 31 of November 2017.

Inclusion criteria for patients are as follows:

1. Age group $18: 50$ years old

2. Regular tramadol use for at least 1 year

3. Acceptance to participate in the study

Inclusion criteria for controls are as follows:

1. Age group 18:50 years old

2. Negative urine screening for the substance of abuse

Exclusion criteria for patients and cross-matched controls (conditions affect level of IL-2) are as follows:

1. Presence of other substances of abuse for patients excluded by addiction severity index (ASI) and urine screening for example abuse of morphine decrease level of IL-2 [2]

2. Individuals with acute or chronic inflammatory conditions proved by raised erythrocyte sedimentation rate (ESR) and CRP
3. Comorbid psychiatric disorder excluded by psychiatric clinical interview and Symptom Check List-90-Revised (the threshold score that needs psychiatric assistance is more than 60 at any domain), for example, there is diminished IL-2 levels in patients with schizophrenia [40]

4. Prior treatment with anti-inflammatory drugs or steroids in the last month

Each patient and control was subjected to the following:

1. Evaluation of sociodemographic characteristics, general medical and neurological examination, and clinical assessment for psychiatric disordersThe socioeconomic status data scale [41] shows that the classification of studied groups was as follows:

a. High socioeconomic class scores are more than 73.6 in the patients and 79.6 in controls.

b. Middle socioeconomic class scores range between 54.4 and 73.6 in the patients and between 53.2 and 79.6 in controls.

c. Low socioeconomic class scores are less than 54.4 in patients and 53.2 in controls.

2. Symptom Check List-90-Revised (SCL-90-R) [42] Translated by Elbehairy (2005).Symptom Check List-90-Revised (SCL-90-R) made out of a 90-item self-report symptom inventory developed by clinical psychometric research. It was designed to identify the psychological symptoms pattern of psychiatric and medical patients. The psychometric analysis was modified and validated in the revised (R) form [42] translated by Elbehairy, [43]. The threshold score that need psychiatric assistance is more than 60 at any domain.

3. Addiction Severity Index [44]: for patients onlyAddiction Severity Index was done for patients only and severity ratings are based on the following 10-point scale (0-9):

- 0-1 no real problem, treatment not indicated

- 2-3 slight problem, treatment probably not necessary

- 4-5 moderate problem, some treatment indicated

- 6-7 considerable problem, the treatment necessary

- 8-9 extreme problem, the treatment necessaryThe severity rating scale enables the interviewer to determine the degree of a client's problem. In each area, the higher the score is, the greater the need for treatment. The ASI scores can be used to identify a client's major problem areas and plan an effective course of treatment [44]. 
4. Laboratory tests including the following:

(a) Urine screening for the substance of abuseSamples are obtained at the time of the first interview with patients and controls to investigate the presence of most common addicting drug groups which are opioids, tramadol, amphetamine, cannabinoids, benzodiazepines, and cocaine.This is done by using the EMIT Drugs-of-Abuse Urine Assays System from Siemens which provides a complete assay for fast analysis of drugs of abuse by using an amino assay technique.

(b) Erythrocyte sedimentation rate (ESR) and Creactive protein $(\mathrm{CRP})$ Blood samples are obtained at the time of the first interview with patients and controls, to exclude presence of any inflammatory conditions.

(c) Quantitation of serum IL-2For patients and controls with a normal range of ESR and CRP during the second interview by using human interleukin-2 (IL-2) ELISA kit of SinoGeneClon Biotech Co., Ltd Catalog no. SG-10261, for the quantitative determination of human IL-2 concentrations by using sandwich ELISA detection method type using serum samples. The detection range was from 50 up to $1000 \mathrm{pg} / \mathrm{ml}$. The sensitivity of the test was $10 \mathrm{pg} / \mathrm{m}$.

\section{Data collection}

The data collection took a period of 1 year, between first of December 2016 and 31st of November 2017, 5 days per week during the morning from 8 am to $2 \mathrm{pm}$. Application of the tools of the study starting by demographic data sheet then Socioeconomic Status Data Scale for patients and controls. After that, general medical and neurological examination, psychiatric clinical interview, and Symptom Check List-90-Revised were done for patients and controls followed by Addiction Severity Index that was done for patients only.

Then drug screening in urine for substance of abuse was done. Samples were obtained at time of admissions for patients and at time of first interview with controls to investigate the most common addicting drug groups and exclude controls with positive results. Also, samples of erythrocyte sedimentation rate (ESR) and C-reactive protein (CRP) are obtained at time of admission for patients and at time of first interview with controls.

Also, quantitation of serum IL-2 was done at the time of the second interview for only controls who have level of ESR and CRP within normal. So of about 100 persons, only 32 were chosen, and at the time of admission for patients who have level of ESR and CRP within normal and positive drug screening for tramadol only, so of about 150 patients, only 59 were chosen.

\section{Statistical analysis}

Data was collected and analyzed using SPSS (Statistical Package for the Social Science, version 20, IBM, Armonk, $\mathrm{NY}$ ). Continuous data were expressed in the form of mean \pm SD or median (range) while nominal data were expressed in the form of frequency (percentage).

Chi-square test was used to compare the nominal data of different groups in the study. While the Student $t$ test was used to compare the mean of different two groups and ANOVA tests for more than two groups. Spearman correlation was used to determine the correlation between different parameters in the study with IL-2. $P$ value was considered significant if $<0.05$.

\section{Results}

This study included 59 male patients and 32 crossmatched male healthy controls. Mean age of the patient group was $28.69 \pm 7.96$ years while it was $30.63 \pm 7.96$ years in the control group. It was noticed that the majority $(57.63 \%)$ of the patient group were married while the majority $(56.2 \%)$ of the controls were single. Significantly higher percentages of patients were skilled workers such as drivers, plumbers, carpenters, and painters $(61.1 \%)$, while significantly higher percentages of controls were an employee (50\%). Most patients (59.3\%) were in low socioeconomic status, while most of the controls (59.4\%) were in middle socioeconomic status.

All demographic data had no significant differences between patient and control except for occupation $(P$ $=0.00)$ and socioeconomic status level $(P=0.002)$ (Table 1).

In this study, the mean age of onset of opioid use disorder (tramadol) was $23.03 \pm 5.70$ years and many patients $(67.8 \%)$ started to use tramadol between the age of 14 and 25 years. The mean daily taken dose was 1243.22 $\pm 629.9 \mathrm{mg}$. The mean duration of use was $5.66 \pm 2.81$ years. As regards urine assay of tramadol in the patient group, it was between 50 and $200 \mathrm{ng} / \mathrm{ml}$ in 17 (28.8\%) of the patients and $>200 \mathrm{ng} / \mathrm{ml}$ in $42(71.2 \%)$ of the patients (Table 2).

Comparing serum level of IL-2 in patients with opioid use disorder (tramadol) with that of the controls, it was found that patients with opioid use disorder (tramadol) have significantly higher serum level of IL-2 (318.69 \pm 35.89) than that of controls $(260.45 \pm 30.08)(\mathrm{P}=0.01)$ (Table 3 and Fig. 1).

Patients with tramadol urine assay $(>200 \mathrm{ng} / \mathrm{ml})$ have significantly higher serum level of IL-2 $(P<0.05)$ which was $357.79 \pm 35.25$ in comparison to $312.93 \pm 27.69$ in patients with tramadol urine assay $(50-200 \mathrm{ng} / \mathrm{ml})$ (Table 4).

Serum level of IL-2 had significant positive correlation with daily dose of tramadol $(r=0.32 ; P=0.02)$ (Fig. 2). 
Table 1 Demographic characteristics of both studied groups

\begin{tabular}{|c|c|c|c|c|c|c|}
\hline \multirow[t]{2}{*}{ Demographic characteristics } & \multicolumn{2}{|c|}{ Patient group $(n=59)$} & \multicolumn{2}{|c|}{ Control group $(n=32)$} & \multirow[t]{2}{*}{$t$ test } & \multirow[t]{2}{*}{$P$ value } \\
\hline & Mean & $\pm \mathrm{SD}$ & Mean & $\pm \mathrm{SD}$ & & \\
\hline \multirow[t]{2}{*}{ Age } & 28.69 & 7.96 & 30.63 & 7.96 & 1.183 & 0.240 \\
\hline & No. & $\%$ & No. & $\%$ & $x^{2}$ & $P$ value \\
\hline \multicolumn{7}{|l|}{ Residence } \\
\hline Rural & 13 & 22.03 & 10 & 31.25 & 0.509 & 0.476 \\
\hline Urban & 46 & 77.97 & 22 & 68.75 & & \\
\hline \multicolumn{7}{|l|}{ Marital status } \\
\hline Single & 23 & 38.99 & 18 & 56.2 & 5.14 & 0.162 \\
\hline Married & 34 & 57.63 & 11 & 34.4 & & \\
\hline Divorced & 1 & 1.69 & 2 & 6.2 & & \\
\hline Widow & 1 & 1.69 & 1 & 3.1 & & \\
\hline \multicolumn{7}{|l|}{ Education level } \\
\hline Illiterate & 11 & 18.6 & 7 & 21.9 & 2.009 & 0.570 \\
\hline Read and write* & 20 & 33.9 & 12 & 37.5 & & \\
\hline Secondary school & 21 & 35.6 & 12 & 37.5 & & \\
\hline University level & 7 & 11.9 & 1 & 3.1 & & \\
\hline \multicolumn{7}{|l|}{ Occupation } \\
\hline Not working & 8 & 13.6 & 3 & 9.4 & 38.569 & 0.000 \\
\hline Non skilled worker* & 3 & 5.1 & 8 & 25 & & \\
\hline Skilled worker* & 36 & 61.1 & 4 & 12.5 & & \\
\hline Employee & 4 & 8.6 & 16 & 50 & & \\
\hline Student & 8 & 13.6 & 1 & 3.1 & & \\
\hline \multicolumn{7}{|l|}{ Socioeconomic status level } \\
\hline Low & 35 & 59.3 & 7 & 21.9 & 12.280 & 0.002 \\
\hline Moderate & 16 & 27.1 & 19 & 59.4 & & \\
\hline High & 8 & 13.6 & 6 & 18.8 & & \\
\hline
\end{tabular}

*Read and write: primary or preparatory school education. Non skilled worker: clean workers and baggers. Skilled worker: work need specific training such as: drivers, plumbers, carpenters, and painters

\section{Discussion}

In the present observational cross sectional study, patients with opioid use disorder (tramadol) have significantly elevated serum levels of interleukin-2 (IL-2) than the healthy controls. Also, this elevation was dose related.

Table 2 Clinical characteristics of patient group

\begin{tabular}{ll}
\hline Clinical characteristics & Patient $(n=59)$ \\
\hline Age of onset (years) & $23.03 \pm 5.70$ \\
$14-25$ years & $40(67.8 \%)$ \\
$>25$ years & $19(32.2 \%)$ \\
Duration (years) & $5.66 \pm 2.81$ \\
Dose (mg/day) & $1243.22 \pm 629.9$ \\
Urine assay & \\
$50-200 \mathrm{ng} / \mathrm{ml}$ & $17(28.8 \%)$ \\
$>200 \mathrm{ng} / \mathrm{ml}$ & $42(71.2 \%)$ \\
\hline
\end{tabular}

Data was expressed in the form of mean \pm SD and frequency (percentage)
Despite that several previous studies examined the effect of opioids dependence on immune functions and serum level of interleukins, a limited number of it focuses on tramadol dependence effect on immune functions and serum level of interleukins. Also, the available studies focused on analgesic doses and their effect on cytokines and natural killer cells; no previous studies focused on high doses or prolonged duration of use and its effect on immune response.

Makimura et al. [45] tried to find out markers that could predict resistance to morphine treatment by measuring the plasma concentrations of cytokines before and after morphine treatment in patients with metastatic cancer. They observed inter-individual variability in baseline plasma cytokine concentrations and found no significant changes in the levels of any cytokine (including interleukin-2 (IL-2)) after 8 days of treatment with morphine in previously opioid-naive patients. Significant change in serum level of cytokines after opioid use could 
Table 3 Serum level of (IL-2) in both studied groups

\begin{tabular}{lllll}
\hline Serum level of IL-2 & Patient group $(n=59)$ & Control group $(n=32)$ & $t$ test & $P$ value* \\
\hline Mean \pm SD & $318.69 \pm 35.89$ & $260.45 \pm 30.08$ & 7.807 & 0.001 \\
\hline$P$ value
\end{tabular}

$P$ value is significant if $<0.05$

* $P$ value compared between patient and control groups

be related to duration of exposure as in the present study and also was reported in the study of Palm et al. [46] who found that the synthesis and secretion of IL-2 by lymphocytes increased significantly after 4 weeks of morphine treatment in patients suffering from chronic pain.

The possibility that the immunologic effects of opioids (morphine) depend on the nature of the exposure has been confirmed in a study of 15 patients with advanced cancer by Hashiguchi et al. [47] who reported that the impact of opioids on immune function might correlate with the duration of opioid use. They found a negative correlation between the levels of morphine metabolites and circulating immunoglobulin levels and the in vitro proliferation of peripheral blood lymphocytes in response to phytohemagglutinin (a nonspecific activator of $T$ cells) in patients who had just started to use morphine. In contrast, no such effects were observed in patients who had been using morphine for over 1 month.

The influence of morphine on immune potential could be dependent on whether it is used acutely or chronically, the route of administration, and the immune parameters that are considered $[48,49]$.

Provinciali et al. [48] studied the short-term immune effects after a single intravenous dose of morphine and the long-term effects after 1 month of oral morphine on NK and lymphokine-activated killer (LAK) cell cytotoxicity in patients with cancer. This study demonstrated that both acute and chronic morphine administration reduced NK cell activity and increased LAK activity. Chronic morphine administration has also been shown to increase the proportion of $\mathrm{CD} 3+$ and $\mathrm{CD} 4+\mathrm{T}$ cells in peripheral blood mononuclear cell preparations, while the prevalence of CD8+ T cells is unaffected and the proportion of CD16+ lymphocytes is reduced. CD16 is a member of the Fc receptor family that is important for the induction of antibody-dependent cellular cytotoxicity (ADCC). Antibody-dependent cellular cytotoxicity is a mechanism of cell-mediated immune defense and a decrease in the presence of such cells could therefore negatively impact tumor surveillance. None of these parameters was affected during acute morphine administration.

Fang and Huang [50] studied the effect of morphine and tramadol on serum level of IL-2 in gynecologic postoperative analgesia and found that both morphine and tramadol could decrease the postoperative pain. In contrast to the suppression of IL-2 level by morphine, tramadol could increase the IL-2 level in post-laparoscopic patients.

Mustafa et al. [51] performed a study to evaluate effect of morphine versus tramadol on the immune response during management of patients with chronic cancer pain. They found that the concentration of IL-2 and INFY in the serum of patients in morphine group was decreased significantly than that in the pre-treatment

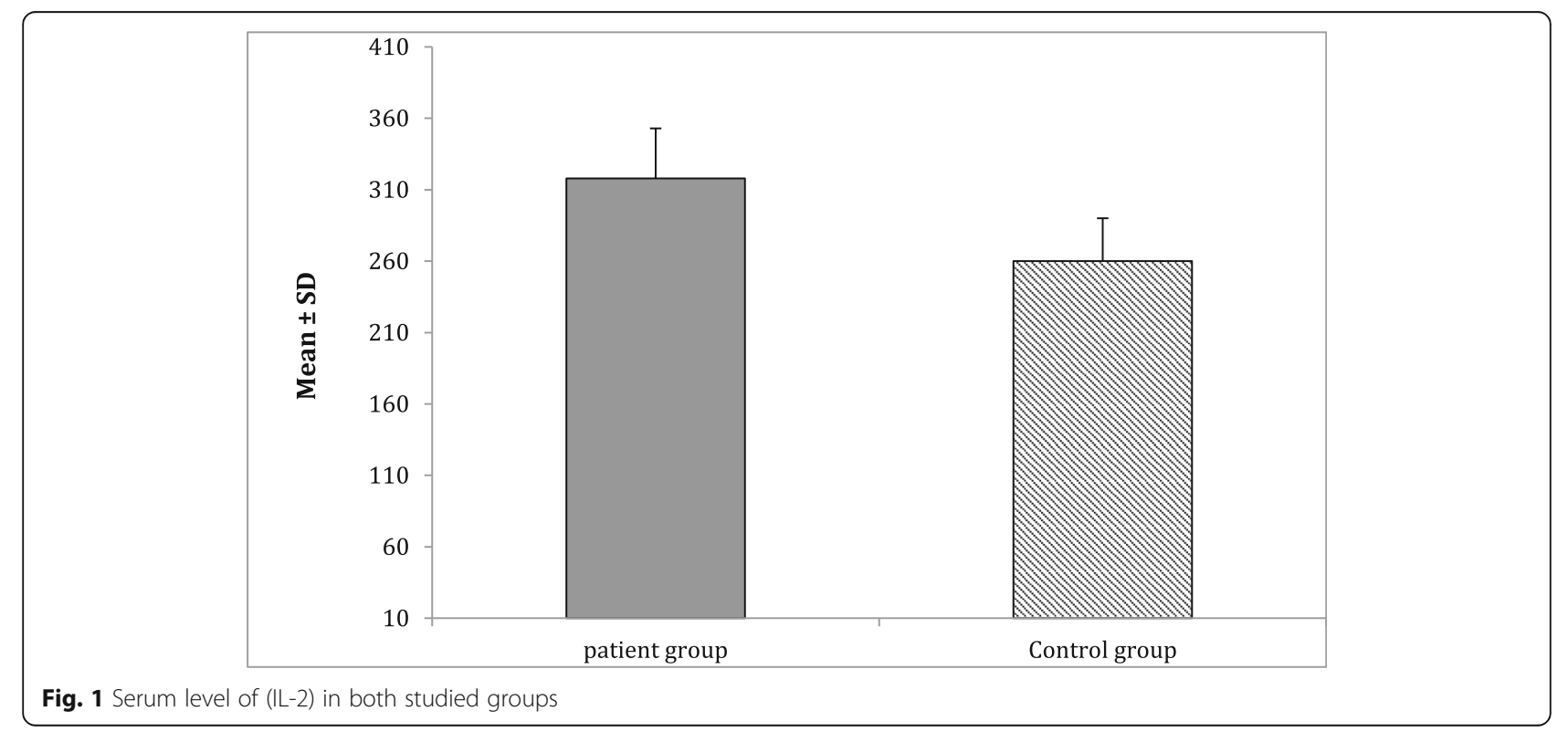


Table 4 Classification of patients according to level of tramadol in urine assay and its relation to serum level of IL-2 in them

\begin{tabular}{llll}
\hline & $\begin{array}{l}\text { Patients with urine assay of tramadol } \\
50-200 \mathrm{ng} / \mathrm{ml}(n=17)\end{array}$ & $\begin{array}{l}\text { Patients with urine assay of tramadol } \\
>200 \mathrm{ng} / \mathrm{ml}(n=42)\end{array}$ & $t$ test \\
& Mean \pm SD & $357.79 \pm 35.25$ & 4.686 \\
\hline Serum level of IL2 & $312.93 \pm 27.69$ & 0.000 \\
\hline
\end{tabular}

phase while increased in the tramadol group than the pretreatment phase and these changes were statistically significant. Both IL-2 and INF $\gamma$ were significantly higher in tramadol group than morphine group along studied periods.

Sacerdote et al. [2] evaluated effects of tramadol on immune responses and pain thresholds in mice and the effects of the acute and chronic intake of tramadol on pain thresholds and on immune responses (by measuring splenocyte proliferation, IL-2 production and natural killer activity) in the mouse. After acute subcutaneous administration, tramadol induced analgesia starting from a dose of $20 \mathrm{mg} / \mathrm{kg}$, whereas it significantly increased natural killer activity and IL-2 production at doses as low as $1 \mathrm{mg} / \mathrm{kg}$ and splenocyte proliferation starting from a dose of $10 \mathrm{mg} / \mathrm{kg}$. After the chronic administration, the analgesic effect of the drug was still present, whereas the immune modifications disappeared. Therefore, the pharmacological characters of tramadol are different from that of other drugs which bind $\mu$-opioid receptors. Their results suggest that tramadol could be a good option for the treatment of pain in patients where immune suppression may be contraindicated.

Liu et al. [52] who studied the effect of tramadol on immune responses and pain thresholds in a rat model of incisional pain found that there was an increase in postoperative serum levels of IL-6, IL-2 which was observed with higher doses of tramadol. However, low doses of tramadol cause a minimal decrease in IL-2 serum level; this was explained by low doses cause no change in IL-2 due to low affinity of tramadol on opioid $\mu$-receptors while high doses act on serotonergic receptors and thus enhance immune-modulation and lead to increase in IL2 . This was consistent with the present study as the daily dose of tramadol in patients ranged from 613 to 1873 $\mathrm{mg} /$ day which is considered a high dose.

Song and Zhao [53] studied IL-2 induced antinociception partially coupled with $\mu$-receptor and found that intraplantar injection of human recombinant interleukin 2 (rIL-2) significantly increased pain threshold to noxious radiant heat in normal rats. rIL-2 antinociception was partially blocked by naloxone in normal rats. So, as that study showed that opioid antagonists cause inhibition of IL-2 production, opioid agonists (including tramadol) may cause induction of IL-2 production.

Wang et al. [54] studied the changes in serum cytokine in response to tramadol in patients undergoing pulmonary lobectomy and found that the group of patients that have undergone pulmonary lobectomy and received tramadol showed higher IL-2 level than those who did not receive tramadol $(P$ value $<0.01)$.

In conclusion, the effect of tramadol on serum level of IL-2 depends on the dose administered and whether it is administered acutely or chronically, and the current study found that patients with tramadol use disorder have significantly elevated serum levels of IL-2 than the healthy controls. Also, this elevation was dose related.

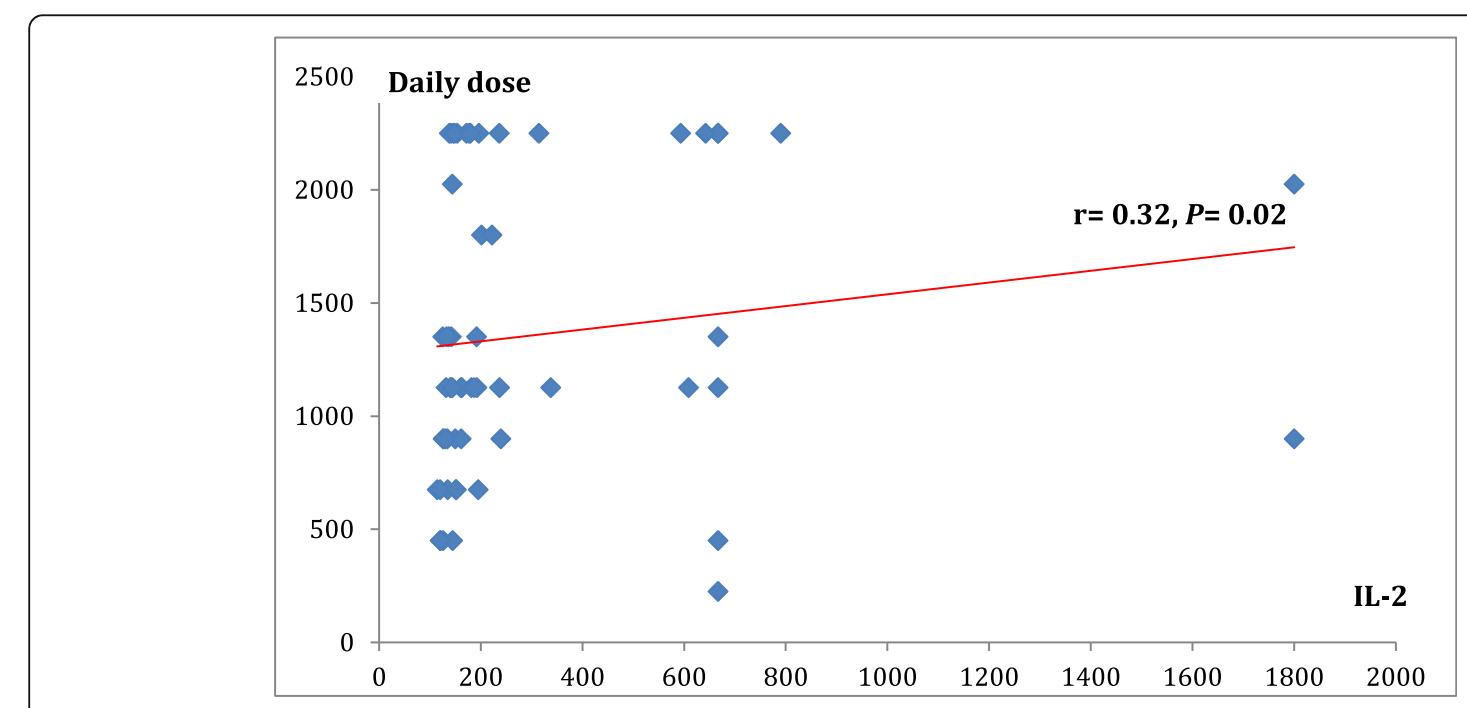

Fig. 2 Correlation between serum level of IL-2 and daily dose of tramadol 
Tramadol improves cellular immune functions mainly the functions of T-lymphocytes subsets and NK cells [55]. The ability of tramadol to enhance immunity could be because of its coexisting intrinsic serotonergic effect $[2,11]$. In spite, serotonin is not required for IL-2 production; increasing serotonin levels above a critical threshold can supplement a suboptimal stimulus to enhance IL-2 production [22]. The effect of tramadol on IL-2 mostly related to its action on serotonergic receptors.

\section{Conclusion}

The current study found that patients with opioid use disorder (tramadol) have significantly elevated serum levels of IL-2 than healthy controls. Also, this elevation was dose related.

Further studies with large sample sizes could be done taking into consideration the relationship between tramadol induced increase in serum level of IL-2 and mesocorticolimbic dopaminergic system.

In patients with a suspected high daily dose of tramadol, serum level of IL-2 might be considered as an indicator.

\section{Abbreviations}

SCL-90-R: Symptom Check List-90-Revised; IL-2: Interleukin-2; ESR: Erythrocyte sedimentation rate; CRP: C-reactive protein; ADCC: Antibody-dependent cellular cytotoxicity; TLR: Toll-like receptor; TNFa: Tumor necrosis factor a; IL1ß: Interleukin-1ß; MCP-1: Monocyte chemo-attractant protein-1

\section{Acknowledgements}

Not applicable.

\section{Authors' contributions}

A. D. contributed in study design, interpretation of the data, and preparing and revising the manuscript. R.H. contributed in study design, assessing, interviewing the patients, collecting, and analyzing and interpreting the data, and prepared the main manuscript. M.A contributed in study design, analyzing, interpretation of the data and writing the manuscript. M.H contributed in assessing, interviewing the patients, collecting, analyzing and interpreting of the data, and revising the manuscript. All authors approved the final manuscript.

\section{Authors' information}

A. D.: Professor of Psychiatry, Neuropsychiatry Department, Faculty of Medicine, Assiut University, Egypt. R. H.: Associate Professor of Psychiatry, Neuropsychiatry Department, Faculty of Medicine, Assiut University, Egypt. M. A.: Professor of Microbiology, Department of Microbiology and Immunology, Faculty of Medicine, Assiut University, Egypt. M. H.: Resident of Psychiatry, Neuropsychiatry Department, Faculty of Medicine, Assiut University, Egypt.

\section{Funding}

The current study was not supported by any national or international institution or organization.

\section{Availability of data and materials}

The data sets generated and/or analyzed during the current study are available from the corresponding author on reasonable request.

\section{Ethics approval and consent to participate}

Before starting data collection, approvals to conduct the study were obtained from the Ethical Review Committee of Assiut Faculty of Medicine and the administrative authority in Neurological and Psychiatric Hospital at Assiut University [56]. Prior to the interview, a written informed consent was obtained from the literate participants and was signed in the presence of witness for illiterate ones. Privacy and secrecy of all data were assured by ensuring anonymity of the questionnaire, interviewing the participant separately in a closed room, and keeping data files in a safe place.

\section{Consent for publication}

Not applicable.

\section{Competing interests}

The authors declare that they have no competing interests.

\section{Author details}

${ }^{1}$ Department of Neuropsychiatry, Assiut University Hospital, Faculty of Medicine, Assiut University, Asyut, Egypt. ${ }^{2}$ Department of Microbiology and Immunology, Faculty of Medicine, Assiut University, Asyut, Egypt.

Received: 23 January 2020 Accepted: 13 May 2020

Published online: 20 July 2020

\section{References}

1. Dayer P, Desmeules J, Collart L (1997) Pharmacologie du tramadol. Drugs 53:18-24

2. Sacerdote $P$, Bianchi M, Manfredi B, Panerai AE (1997) Effects of tramadol on immune responses and nociceptive thresholds in mice. Pain 72:325-330

3. Hennies H, Friderichs E, Schneider J (1988) Receptor binding, analgesic and antitussive potency of tramadol and other selected opioids. Arzneimittelforschung 38:877-880

4. Paar W, Frankus P, Dengler H (1992) The metabolism of tramadol by human liver microsomes. Clin Invest 70:708-710

5. Kayser V, Besson J-M, Guilbaud G (1992) Evidence for a noradrenergic component in the antinociceptive effect of the analgesic agent tramadol in an animal model of clinical pain, the arthritic rat. Eur J Pharmacol 224:83-88

6. Raffa RB, Friderichs E, Reimann W, Shank RP, Codd EE, Vaught JL (1992) Opioid and nonopioid components independently contribute to the mechanism of action of tramadol, an 'atypical' opioid analgesic. Pharmacol Exp Ther 260:275-285

7. Driessen B, Reimann W (1992) Interaction of the central analgesic, tramadol, with the uptake and release of 5-hydroxytryptamine in the rat brain in vitro. Br J Pharmacol 105:147-151

8. Driessen B, Reimann W, Giertz H (1993) Effects of the central analgesic tramadol on the uptake and release of noradrenaline and dopamine in vitro. Br J Pharmacol 108:806-811

9. Dayer P, Collart L, Desmeules J (1994) The pharmacology of tramadol. Drugs 47:3-7

10. Besson J-M, Vickers MD (1994) Tramadol analgesia. Synergy in research and therapy. Drugs 47:1

11. Gaspani L, Bianchi M, Limiroli E, Panerai AE, Sacerdote P (2002) The analgesic drug tramadol prevents the effect of surgery on natural killer cell activity and metastatic colonization in rats. J Neuroimmunol 129:18-24

12. Sacerdote P, Bianchi M, Gaspani L, Panerai A (1999) Effects of tramadol and its enantiomers on Concanavalin-A induced-proliferation and NK activity of mouse splenocytes: involvement of serotonin. Int J Immunopharmacol 21: 727-734

13. Sacerdote P, Bianchi M, Gaspani L, Manfredi B, Maucione A, Terno G, Ammatuna M, Panerai AE (2000) The effects of tramadol and morphine on immune responses and pain after surgery in cancer patients. Anesth Analg 90:1411-1414

14. Niemand C, Nimmesgern A, Haan S, Fischer P, Schaper F, Rossaint R, Heinrich PC, Muller-Newen G (2003) Activation of STAT3 by IL-6 and IL-10 in primary human macrophages is differentially modulated by suppressor of cytokine signaling 3. J Immunol 170:3263-3272

15. Sheeran P, Hall G (1997) Cytokines in anaesthesia. Br J Anaesth 78:201-219

16. Mier JW, Gallo RC (1980) Purification and some characteristics of human Tcell growth factor from phytohemagglutinin-stimulated lymphocyteconditioned media. Proc Natl Acad Sci U S A 77:6134-6138

17. Kolitz, J., Mertelsmann, R., Sykora, K. \& Welte, K. J. C. B. 1987. Interleukin-2: basic and clinical studies. 39, 13-18.

18. Granelli-Piperno A, Andrus L, REICH EJJOEM (1984) Antibodies to interleukin 2. Effects on immune responses in vitro and

19. Roediger B, Kyle R, Tay SS, Mitchell AJ, Bolton HA, Guy TV, Tan S-Y, ForbesBlom E, Tong PL, Köller YJJO (2015) IL-2 is a critical regulator of group 2 
innate lymphoid cell function during pulmonary inflammation. J Allergy Clin Immunol 136:1653-1663.e7

20. Bleackley RC, Barr PJ, Havele C, Hooton J, Ng J, Meier M, Merryweather JP, Gibbs C, Paetkau V (1985) Biologic activities of recombinant human interleukin 2 on murine lymphocytes. Lymphokine Res 4:117-131

21. Whiteside TL, Herberman RB (1989) The role of natural killer cells in human disease. Clin Immunol Immunopathol 53:1-23

22. Young M, Kut J, Coogan M, Wright M, Young M, Matthews J (1993) Stimulation of splenic T-lymphocyte function by endogenous serotonin and by low-dose exogenous serotonin. Immunology 80:395

23. Hellstrand K, Hermodsson SJCI (1990) Enhancement of human natural killer cell cytotoxicity by serotonin: role of non-T/CD16+ NK cells, accessory monocytes, and 5-HT1A receptors. 127:199-214

24. Hellstrand K, Hermodsson SJSJ (1990b) Monocyte-mediated suppression of IL-2-induced NK-cell activation: regulation by 5-HT1A-type serotonin receptors. 32:183-192

25. Hernandez ME, Mendieta D, Perez-Tapia M, Bojalil R, Estrada-Garcia I, Estrada-Parra S, Pavón L (2013) Effect of selective serotonin reuptake inhibitors and immunomodulator on cytokines levels: an alternative therapy for patients with major depressive disorder. Clin Dev Immunol 2013:267871

26. Nestler EJ (2001) Molecular basis of long-term plasticity underlying addiction. Nat Rev Neurosci 2:119

27. Connor B, Dragunow M (1998) The role of neuronal growth factors in neurodegenerative disorders of the human brain. Brain Res Brain Res Rev 27:1-39

28. Neumann $H$, Schweigreiter R, Yamashita T, Rosenkranz K, Wekerle $H$, Barde Y-A (2002) Tumor necrosis factor inhibits neurite outgrowth and branching of hippocampal neurons by a rho-dependent mechanism. J Neurosci 22: 854-862

29. Robinson TE, Kolb B (1997) Persistent structural modifications in nucleus accumbens and prefrontal cortex neurons produced by previous experience with amphetamine. J Neurosci 17:8491-8497

30. Zalcman SS (2001) Interleukin-2 potentiates novelty-and GBR 12909-induced exploratory activity. Brain Res 899:1-9

31. Ho B, Lu J-G, Huo Y-Y, Fan S, Meyers C, Tansey L, Payne R, Levin V (1994) Neurochemical basis of interleukin 2-modified discrimination behaviour. Cytokine 6:365-367

32. Mita $Y$, Dobashi $K$, Endou K, Kawata T, Shimizu Y, Nakazawa T, Mori MJIL (2002) Toll-like receptor 4 surface expression on human monocytes and $B$ cells is modulated by IL-2 and IL-4. 81:71-75

33. Candia L, Marquez J, Hernandez C, Zea AH, Espinoza LRJT (2007) Toll-like receptor-2 expression is upregulated in antigen-presenting cells from patients with psoriatic arthritis: a pathogenic role for innate immunity? 34 : 374-379

34. Crews FT, Vetreno RPJP (2016) Mechanisms of neuroimmune gene induction in alcoholism. 233:1543-1557

35. Crews FT, Walter TJ, Coleman LG, Vetreno RPJP (2017) Toll-like receptor signaling and stages of addiction. 234:1483-1498

36. Miotto K, Cho AK, Khalil MA, Blanco K, Sasaki JD, Rawson R (2017) Trends in tramadol: pharmacology, metabolism, and misuse. Anesth Analg 124:44-51

37. Hamdi E, Gawad T, Khoweiled A, Sidrak AE, Amer D, Mamdouh R, Fathi H, Loza NJSA (2013) Lifetime prevalence of alcohol and substance use in Egypt: a community survey. 34:97-104

38. Abolmaged S, Kodera A, Okasha T, Gawad T, Rawson RJCJOA (2013) Tramadol use in Egypt: emergence of a major new public health problem. 4:5

39. OpenEpi, Version 3, open source calculator-SSPropor at 11 June 2016-11: 15P.M.

40. Asevedo E, Rizzo LB, Gadelha A, Mansur RB, Ota VK, Berberian AA et al (2014) Peripheral interleukin-2 level is associated with negative symptoms and cognitive performance in schizophrenia. Physiol Behav 129:194-198

41. Tawab A-e (2004) Socioeconomic status scale, Faculty of education, department of psychology, Assiut University

42. Derogatis LR, Rickels K, Rock A (1976) The SCL-90 and the MMPI: a step in the validation of a new self-report scale. Br J Psychiatry 128(3):280-289

43. El-Behairy A (2005) Arabic version of CFSEIAD form, Educational and psychological research center, Assiut University. Mochtar Press, Assiut

44. Mclellan AT, Luborsky L, O'Brien CP, Woody GEJN (1980) An improved diagnostic instrument for substance abuse patients: the Addiction Severity Index. 168:26-33

45. Makimura C, Arao T, Matsuoka H, Takeda M, Kiyota H, Tsurutani J, Fujita Y, Matsumoto K, Kimura H, Otsuka MJAR (2011) Prospective study evaluating the plasma concentrations of twenty-six cytokines and response to morphine treatment in cancer patients. 31:4561-4568

46. Palm S, Lehzen S, Mignat C, Steinmann J, Leimenstoll G, Maier C (1998) Does prolonged oral treatment with sustained-release morphine tablets influence immune function? Anesth Analg 86:166-172

47. Hashiguchi S, Morisaki H, Kotake Y, Takeda JJJO (2005) Effects of morphine and its metabolites on immune function in advanced cancer patients. 17: $575-580$

48. Provinciali M, Di Stefano G, Stronati S, Raffaeli W, Pari G, Fabris NJIJ (1996) Role of prolactin in the modulation of NK and LAK cell activity after short-or long-term morphine administration in neoplastic patients. 18:577-586

49. Keiser MJ, Setola V, Irwin JJ, Laggner C, Abbas Al, Hufeisen SJ, JENSEN NH, Kuijer MB, Matos RC, Tran TBJN (2009) Predicting new molecular targets for known drugs. 462:175

50. Fang $\mathrm{G}$, Huang $T$ (2003) Effect of morphine and tramadol on IL-2 in gynecologic postoperative analgesia. 27(5):247-248

51. Mostafa M, Mors K, Rahman MA, Ahmad HJ (2012) Effect of morphine versus tramadol on the immune response during the management of patients with chronic cancer pain. 5(2):156-160

52. Liu Y-M, Zhu S-M, Wang K-R, Feng Z-Y, Chen Q-LJJ (2008) Effect of tramadol on immune responses and nociceptive thresholds in a rat model of incisional pain. 9:895-902

53. Song P, Zhao ZJC (2000) Interleukin 2-induced antinociception partially coupled with $\mu$ receptor. 12:1240-1242

54. Wang G, Weng Y, Ishiguro Y, Sakamoto H, Morita SJJO (2005) The effect of tramadol on serum cytokine response in patients undergoing pulmonary lobectomy. 17:444-450

55. Zhou L, Ding H, Li M (2013) Effect of tramadol on perioperative immune function in patients undergoing gastric cancer surgeries. 1:17-54

56. The official site of Assiut University [Internet]. 2019. Available from: www. aun.edu.eg.

\section{Publisher's Note}

Springer Nature remains neutral with regard to jurisdictional claims in published maps and institutional affiliations.

\section{Submit your manuscript to a SpringerOpen ${ }^{\odot}$ journal and benefit from:}

- Convenient online submission

- Rigorous peer review

- Open access: articles freely available online

- High visibility within the field

- Retaining the copyright to your article

Submit your next manuscript at $>$ springeropen.com 